\title{
Feasibility of salt reduction in processed foods in Argentina
}

\author{
Daniel Ferrante, ${ }^{1}$ Nicolas Apro, ${ }^{2}$ Veronica Ferreira, ${ }^{2}$ Mario Virgolini, ${ }^{1}$ \\ Valentina Aguilar, ${ }^{2}$ Miriam Sosa, ${ }^{2}$ Pablo Perel, ${ }^{3}$ and Juan Casas ${ }^{3}$
}

Suggested citation Ferrante D, Apro N, Ferreira V, Virgolini M, Aguilar V, Sosa M, et al. Feasibility of salt reduction in processed foods in Argentina. Rev Panam Salud Publica. 2011;29(2):69-75.

ABSTRACT Objective. To assess an intervention to reduce salt intake based on an agreement with the food industry.

Methods. Salt content was measured in bakery products through a national survey and biochemical analyses. Low-salt bread was evaluated by a panel of taste testers to determine whether a reduced salt bread could remain undetected. French bread accounts for $25 \%$ of the total salt intake in Argentina; hence, reducing its salt concentration from $2 \%$ to $1.4 \%$ was proposed and tested. A crossover trial was conducted to evaluate the reduction in urinary sodium and blood pressure in participants during consumption of the low-salt bread compared with ordinary bread.

Results. Average salt content in bread was 2\%. This study evaluated low-salt bread containing $1.4 \%$ salt. This reduction remained mostly undetected by the panels of taste testers. In the crossover trial, which included 58 participants, a reduction of 25 milliequivalents in 24hour urine sodium excretion, a reduction in systolic blood pressure of $1.66 \mathrm{mmHg}$, and a reduction in diastolic blood pressure of $0.76 \mathrm{mmHg}$ were found during the low-salt bread intake. Conclusions. The study showed that dietary salt reduction was feasible and well accepted in the population studied through a reduction of salt content in bread. Although the effects on urinary sodium and blood pressure were moderate, a countrywide intervention could have a greater public health impact.

Key words Sodium, dietary; food habits; nutrition policy; bread; blood pressure; Argentina.

In countries with low adult mortality and medium infant mortality (1), high blood pressure is the leading cause of death. Hypertension is estimated to cause 50000 deaths per year in Argentina (2).

Salt intake is a main determinant of elevated blood pressure and is associated with the increase in blood pressure re-

\footnotetext{
1 Ministry of Health, Health Promotion, Buenos Aires, Argentina. Send correspondence to Daniel Ferrante, dferrante@msal.gov.ar

2 Instituto Nacional de Tecnología Industrial, Centro de Cereales y Oleaginosas, San Martín, Argentina.

3 London School of Hygiene and Tropical Medicine, London, United Kingdom.
}

lated to aging (3) and increased risks of stroke and coronary heart disease (4).

Salt reduction based mainly on voluntary agreements with the food industry is considered one of the most costeffective interventions (5). Populationbased observational studies and community trials have shown a direct relationship between salt consumption and blood pressure in the population (6).

Interventions aimed at reducing salt intake at the individual level have been shown to effectively reduce blood pressure, as described in a meta-analysis of long-term randomized trials (7). How- ever, the medical advice needed to achieve a significant reduction in salt intake requires intensive interventions and is not feasible for primary health care settings (8). Moreover, intense individual intervention has low feasibility in developing countries because of a lack of resources (8) and low external validity (9). However, these interventions provide an estimate of a decreased risk of events by reducing salt intake (10).

Population-based education and mass media interventions (11-15) have shown reductions in salt intake. Moreover, reductions in blood pressure observed in 
European MONICA (monitoring trends and determinants in cardiovascular disease) cohorts were attributed not to use of antihypertensive drugs but to reduced salt intake and other lifestyle modifications (16).

Although evidence from developed countries indicates that populationbased salt reduction policies, especially focused on sodium reduction in processed foods, may be feasible (17), data about the effectiveness and the impact of such interventions remain limited in developing countries. Experiences in developing countries did not include structured approaches to reducing salt levels in processed foods, which can be a less expensive and more straightforward way to reduce salt intake than mass media and educational activities, which maintain their effect only while they are in place (18).

In Argentina, one in three adults has elevated blood pressure, and hypertension diagnosis and treatment are not optimal (19). Health authorities are committed to improving primary health care of hypertensive subjects and to reducing salt intake in the population. This may be achieved by reducing the salt content in processed foods and by launching educational and community interventions and mass media campaigns targeted at changing dietary habits (20).

Argentineans eat nearly $12 \mathrm{~g}$ of salt per day, $65 \%$ to $70 \%$ of which comes from processed foods (21). Bread constitutes an important source of salt intake, as the mean daily bread consumption is $190 \mathrm{~g}$ per capita, and the estimated mean salt content is about 2\% (22), which amounts to $25 \%$ ( $4 \mathrm{~g}$ ) of the total salt intake. This fact provides an opportunity to take action with a single sector in order to obtain benefits for the general population (23).

This study assessed the baseline status of salt content in bakery products and evaluated the potential impact of salt reduction based on technological aspects and consumers' preferences. Then, the suggested reduction was implemented and intermediate outcomes were assessed mainly through 24-hour urinary sodium analysis, which is considered the gold standard for estimating sodium intake. For this report, salt is mentioned when referring to food products, and sodium ( $40 \%$ of salt is sodium) is mentioned when referring to urinary analyses.

\section{METHODS}

The study was conducted in 2006 and 2007 and had three phases: 1) analysis of salt content in bakery products in a sample of bakeries throughout the country, 2) development of reduced salt bread with a panel of taste testers and food technology assessments, and 3) a crossover trial to assess the feasibility and impact of the intervention.

\section{Analysis of salt content in bakery products}

The salt content in bakery products was assessed in a representative sample of bakeries from Argentina affiliated with a national federation, the Argentinean Federation of Bakeries (FAIPA). The sampling frame of bakeries includes the 25000 bakeries countrywide affiliated with FAIPA. A probabilistic sample design was followed, and bakeries were randomly selected to estimate an expected mean salt content of $2 \mathrm{~g}$ per $100 \mathrm{~g}$ of final product in French bread, with an error of $0.1 \mathrm{~g}$. A sample of 1250 bakeries was required.

Measurements performed in each selected bakery included a questionnaire and biochemical analyses. The selfadministered questionnaires were mailed to the respondents. Questions included the amount of salt used per kilogram of flour and per final product and knowledge of salt functions in bakery products and interest in participating in the elaboration of products with lower salt content.

For biochemical analyses, a random subsample of only 26 bakeries was included because of financial constraints. Flame photometric determination of salt concentration was used with validated equipment at the National Institute of Industrial Technology (24). The purpose of these measurements was to estimate potential bias in reporting the salt content of French bread (the most consumed product), not to obtain a national mean value. The mean value, range, and deviation between the real value and the selfreported value were estimated.

\section{Development of reduced salt bread}

At this stage, a formula was developed to make lower-salt bakery products. For the sensory analysis, two panels were formed: a 20-participant expert panel of taste testers and a panel of 100 participants from the community. Salt levels in breads tested by the panels ranged from 0.6 to $4.2 \mathrm{~g}$ per $\mathrm{kg}$ of bread.

The objective of the expert panel analysis was to obtain a threshold of salt reduction that would remain undetected by consumers. The expected outcome was a $20 \%$ to $25 \%$ decrease in the salt content of bread.

Expert panel members were part of the staff of the Food Technology Institute from the city of 9 de Julio. Their objective was to establish a concentration of salt in bread that remained undetected from the control. The control bread had a salt concentration that was the average obtained from the surveys and analyses from bakeries.

The 20 selected panelists blind-tasted four pairs of bread in each session (25). In each pair, one slice of bread was the control (i.e., $1.8 \%$ salt) and the other had a salt concentration ranging from $1.0 \%$ to $1.8 \%$. For statistical analysis, the chisquared test was used.

The consumer panel included 100 men and women of different age groups from the city of 9 de Julio who were invited to participate, mostly consumers contacted at the bakeries. The purpose of this panel was to establish a salt concentration that ordinary consumers would accept. Consumers participated in two sessions. First, they tasted seven breads with salt concentrations ranging from $0.6 \%$ to $4.2 \%$ in a blinded manner. After they tried the breads, an acceptance zone was developed according to their opinions between two thresholds: rejection zone for low-salt flavor and rejection zone for salty flavor. The optimum salt content was determined as that having the smallest rejection rate. Each bread was scored by panelists between 1 ("I do not like it, it is horrible") and 10 ("I like it a lot"). Analysis of variance models were used to test differences in acceptability (26).

Second, consumers participated in paired comparison trials. Fifty consumers tested $1.6 \%$ and $1.8 \%$ salt-containing bread and the other 50 tested $1.5 \%$ and $1.8 \%$ salt-containing bread. This stage was developed to determine whether a moderate salt reduction-from the average market salt level-could remain undetected. Results were statistically significant when all $P$ values were less than 0.05 .

The final recommendation of both panels was to achieve a salt level that represented a significant decrease in salt 
intake but that could also be well accepted and tested for reduction of salt intake in the third phase.

\section{Crossover trial to assess the feasibility and impact of the intervention}

Objectives. The main objective of the third phase was to assess the impact of the salt reduction intervention in French bread in the city of 9 de Julio.

Design. A randomized $2 \times 2$ crossover trial was designed with one group randomly assigned to a normal-to-low-salt bread sequence and the other group to a low-to-normal-salt bread sequence (27). Normal-salt bread contained 2.0\% salt, and low-salt bread contained $1.4 \%$ salt, based on the results of the panels of taste testers.

Population. Adults aged 18 years or older from the adult population living in the city of 9 de Julio, Argentina, were included. Adults working in the health sector and in the municipality were invited to participate in the study. Participants were recruited and randomized at local hospital facilities, where the assessments took place. Participants did not receive economic incentives.

Inclusion criteria were systolic blood arterial pressure between $120 \mathrm{mmHg}$ and $159 \mathrm{mmHg}$, normotensive or hypertensive participants under treatment without changes in treatment or diet during the last month, and consumption of bread.

Exclusion criteria were symptomatic heart disease, renal failure or blood creatinine concentration higher than $1.5 \mathrm{mg}$ per $\mathrm{dL}$, use of diuretics, diabetes mellitus treatment with insulin, special dietary requirements such as a prescribed verylow-salt diet or celiacs, consumption of more than one alcoholic drink a day, and any other condition that in the investigators' opinion did not allow the patient to be included.

Procedures and measurements. Trial duration was 35 days. On the first visit, baseline data were obtained and participants were randomized by telephone using a centralized telephone system. Subjects were randomized to either a normal-to-low-salt bread sequence or to a low-to-normal-salt one. Each stage lasted 15 days, with a 5-day washout period.

All participants were instructed to continue their diets during the study with- out changing the amount or type of salt used. However, they were advised to avoid foods with a very high salt content if they did not usually consume them. They were also instructed to report any changes in their blood pressure medications. Participants received a diary where they reported daily food intake.

Four bakeries participated in the study. Participants continued to purchase bread on a daily basis from their usual bakeries where the personnel assigned French bread with an unknown concentration of salt to the participants. Evaluators were also blinded to the sequence.

At baseline, after the first phase, and after the second phase, participants collected repeated 24-hour urine samples and health professionals measured their blood pressure. Patients were instructed to follow routine recommendations before blood pressure measurements. At each visit, two measurements of rightarm blood pressure were performed by trained personnel using international standards (28).

\section{Ethics}

The protocol was approved by a local ethics committee. All subjects provided written informed consent and were free to withdraw from the study at any time. Data retrieved from subjects were confidential.

\section{Statistical analyses: sample size and tests}

Baseline data were described using proportions for categorical variables and means and standard deviations for continuous variables. The following linear model was used to analyze the crossover trial (29):

$$
\begin{gathered}
Y_{i j k}=\mu+\text { sequence }_{i}+\text { subject }_{i j}+\text { period }_{k} \\
+ \text { treatment }_{h}+e_{i j k}
\end{gathered}
$$

where

$Y_{i j k}=$ sodium concentration in urine (or systolic and diastolic blood pressure, according to each of the three models used) for each subject, sequence, and period;

$\mu=$ overall mean of sodium concentration (or systolic and diastolic blood pressure, same as above); and

$e_{i j k}=$ error term for each subject, sequence, and period.
Mean urinary 24-hour sodium excretion was the dependent variable. A linear model was built to test the hypothesis of no difference between low-salt and normal-salt bread diets on 24-hour urinary excretion. Blood pressure (systolic and diastolic) was included in another analysis with a similar linear model. The sequence effect was tested to assess carryover effects.

The potential reduction in salt intake implied a reduction of salt in bread of 1.0 to $1.2 \mathrm{~g}$ per day (the expected value before the survey and before the panels of taste testers). This value could explain a reduction of 20 milliequivalents (meq) in 24-hour sodium excretion according to previous studies (30). Considering a standard deviation of 45 meq per day, a sample of at least 54 patients was needed in a crossover comparison to detect this difference, with $80 \%$ power and an alpha error of $5 \%$. The software $\mathrm{R}$ was used for all statistical analyses.

\section{RESULTS}

\section{Phase 1: questionnaire and analytical results}

Of the 25000 bakeries, 1250 were included in the sample. Since approximately 1500 bakeries were invited, the response rate was $83.3 \%$. The bakeries included were from all around the country and varied in size. Bakeries in Argentina are usually small family businesses, and no big chains are operating in the market. The assessment, as reported by the bakers, provided the following average salt contents: French bread $=1.8 \%$ (range $1.0 \%$ to $4.0 \%$ ), croissants and cookies $=1.8 \%$ (range $1.0 \%$ to $3.5 \%$ ), crackers $=2.9 \%$ (range $2.2 \%$ to $5.0 \%)$, and flat rounded crackers $=2.1 \%$ (range $1.2 \%$ to $3.4 \%$ ). Only French bread samples were chemically analyzed. The average of the 26 samples analyzed suggested a mean salt concentration of $0.8 \%$, equivalent to a salt content of $2.0 \%$ in French bread, ranging from $1.4 \%$ to $3.0 \%$. The difference between selfreported salt content and measured salt content was $0.2 \%$.

There was considerable variability among the different bakeries, which implies a wide variety of methodologies and recipes (data not shown).

Regarding the perceptions of bakers about the role of salt in bread making, $92.2 \%$ reported a role in flavor, $67.4 \%$ a 
role in color, $30.7 \%$ a role in water and gas retention, $22.3 \%$ a role in elasticity, $49.9 \%$ affecting yeast activity, $24.5 \%$ affecting acidity, and $49.8 \%$ having a role in the crusty cortex.

\section{Phase 2: expert panel of taste testers and consumers}

Panelists were able to detect when bread had a salt content lower than $1.4 \%$ $(P=0.132)$ (Table 1$)$. Most expert panelists detected lower salt concentrations when bread had less than $1.4 \%$ salt.

A control sample with a salt content of $1.8 \%$ was used for all comparisons. The estimation of salt concentration in bread detected as less salty was $1.4 \%$. The recommended concentration was $1.4 \%$ to $1.5 \%$ salt to be adopted for further testing with regular consumers.

Consumers rated seven French breads with different salt concentrations (ranging from $0.6 \%$ to $4.2 \%$ ) (Table 2 ). Bread with salt concentrations of $1.8 \%, 2.4 \%$, and $3.0 \%$ had more consumer acceptance. The samples with lower acceptance had either very low $(0.6 \%)$ or very high $(4.2 \%)$ salt concentrations.

In a different session, 50 consumers tried and compared two breads, with salt contents of $1.8 \%$ and $1.5 \%$, and the other 50 evaluated breads with salt contents of $1.8 \%$ and $1.6 \%$. There were no significant differences in consumers' preferences in both comparisons $(1.8 \%$ vs. $1.5 \% P=0.08,1.8 \%$ vs. $1.6 \% P=0.1$ ).

Although the bread with $1.4 \%$ salt was not the most accepted, the difference between the usual concentration $(1.8 \%$ to $2 \%$ ) and $1.4 \%$ was mostly undetected and fairly well accepted.

Therefore, bread with $1.4 \%$ salt content was tested in the crossover trial to assess its potential to reduce overall salt intake.

Phase 3: results from crossover trial on urinary sodium and blood pressure

In this phase, 98 volunteers were screened, and 58 signed the informed consent. Of the 40 subjects who were not included, 16 were disqualified because of the presence of exclusion criteria (10 required low-salt diets, 3 were using diuretics, and 3 consumed more than one alcoholic drink per day) and 24 declined to participate, mainly because they did not want to collect 24-hour urine samples. Nonparticipants were mainly men

TABLE 1. Results from expert panel of taste testers $(n=20)$ : identification of lower-salt breads compared with control (1.8\% salt), Argentina, 2007

\begin{tabular}{ccc}
\hline $\begin{array}{c}\text { Salt concentration } \\
\text { in bread sample } \\
(\%)\end{array}$ & $\begin{array}{c}\text { Number of panelists } \\
\text { who correctly identified } \\
\text { lower-salt bread }\end{array}$ & P value \\
\hline 1.0 & 19 & $<0.0001$ \\
1.1 & 19 & $<0.001$ \\
1.2 & 16 & 0.006 \\
1.3 & 17 & 0.001 \\
1.4 & 13 & 0.132 \\
1.5 & 15 & 0.021 \\
1.6 & 12 & 0.252 \\
1.7 & 13 & 0.132 \\
\hline
\end{tabular}

TABLE 2. Results from panel of consumers: average acceptability for each bread sample (scale of 1-10), Argentina, 2007

\begin{tabular}{cc}
\hline $\begin{array}{c}\text { Salt concentration } \\
\text { in bread sample (\%) }\end{array}$ & $\begin{array}{c}\text { Average score of acceptability } \\
\text { among } 100 \text { consumers }\end{array}$ \\
\hline 0.6 & $4.3^{\mathrm{a}}$ \\
1.2 & $5.5^{\mathrm{b}}$ \\
1.8 & $6.5^{\mathrm{c}, \mathrm{d}}$ \\
2.4 & $7.0^{\mathrm{d}}$ \\
3.0 & $6.9^{\mathrm{d}}$ \\
3.6 & $5.8^{\mathrm{b}, \mathrm{c}}$ \\
4.2 & $4.9^{\mathrm{a}, \mathrm{b}}$
\end{tabular}

Note: Levels of salt with the same letters indicate no difference in multiple comparisons by analysis of variance.

(72.5\%) and younger (mean age 32 years) than the subjects included in this phase.

Of the 58 subjects, 29 were randomly assigned to a normal-to-low-salt bread sequence and 29 were assigned to a lowto-normal-salt bread sequence.

Baseline population characteristics are provided in Table 3. Participants purchased daily bread from their bakeries as mentioned above.

Baseline urinary excretion in the 58 subjects was 160 meq per day (range 60-288, standard deviation 53). Mean age was 39 years, $29.1 \%$ were men, hypertension was present in $34.6 \%$ of participants, and $18.1 \%$ of participants were already controlling salt in their diet. However, $69.1 \%$ of participants reported cooking with salt and $34.3 \%$ said they always added salt to their meals (Table 3 ).

Compared with the normal-salt bread diet, the low-salt bread diet was associated with a reduction of $25.3 \mathrm{meq}$ in 24-hour urinary sodium $(95 \%$ confidence interval [CI] 6.9 to $43.7, P=0.0086$ ) (Table 4) (Figure 1). Neither order nor sequence was significant.

Although it was not the main outcome of the study, systolic blood pressure was compared between groups. Systolic blood pressure decreased $1.66 \mathrm{mmHg}$ with the low-salt bread diet (95\% CI 0.52-2.74, $P=0.0059)$. Neither order nor sequence was significant, providing no evidence of carryover effects.

There was also a small but significant reduction in diastolic blood pressure of $0.76 \mathrm{mmHg}$ (95\% CI $0.08-1.44$, $P=0.0297)$ during the low-salt bread periods. No significant sequence or order effect was observed in blood pressure comparisons.

\section{DISCUSSION}

Baseline salt content in bakery products was high and had wide variability among bakeries nationwide. In general, bakers did not know that the main role of salt in bakery products is for flavor, and most of them prepared their products without measuring the salt they added.

A bread with lower salt content could be developed and remain undetected compared with regular bread even after a significant salt reduction There was fairly good acceptability among consumers of bread with lower salt content.

The low-salt bread showed urinary sodium reductions in a sample of volun- 
TABLE 3. Baseline characteristics of participants in a crossover trial of low and normal levels of salt in bread, Argentina, 2007

\begin{tabular}{|c|c|c|c|}
\hline Characteristic & $\begin{array}{l}\text { High to low salt } \\
\qquad(n=29)\end{array}$ & $\begin{array}{l}\text { Low to high salt } \\
\qquad(n=29)\end{array}$ & $P$ value \\
\hline Females (\%) & 62.9 & 78.5 & 0.2 \\
\hline Mean age $\pm S D$ (years) & $41.5 \pm 12.4$ & $37.1 \pm 9.1$ & 0.13 \\
\hline \multicolumn{4}{|l|}{ With elevated blood pressure or treatment for } \\
\hline hypertension (\%) & 40.7 & 28.6 & 0.34 \\
\hline Use salt in cooking (\%) & 74.1 & 64.3 & 0.43 \\
\hline Use salt at table (\%) & 22.2 & 46.3 & 0.06 \\
\hline Consume low-salt diet (\%) & 25.9 & 10.7 & 0.14 \\
\hline \multicolumn{4}{|l|}{ Mean baseline sodium excretion \pm SD } \\
\hline (milliequivalents/24 hours) & $158.6 \pm 47.2$ & $160.3 \pm 58.9$ & 0.86 \\
\hline Mean baseline systolic blood pressure $\pm \mathrm{SD}(\mathrm{mmHg})$ & $114.4 \pm 11.6$ & $113.8 \pm 10.5$ & 0.85 \\
\hline Mean baseline diastolic blood pressure $\pm \mathrm{SD}(\mathrm{mmHg})$ & $66.3 \pm 5.4$ & $67.4 \pm 6.1$ & 0.45 \\
\hline
\end{tabular}

Note: SD: standard deviation.

TABLE 4. Change in urinary sodium and blood pressure for low and normal levels of salt in bread: 24-hour urine sodium and blood pressure in 58 participants (paired comparisons in crossover trial), Argentina, 2007

\begin{tabular}{ccccc}
\hline Outcome & $\begin{array}{c}\text { Normal-salt bread } \\
\text { (mean } \pm \text { SD) }\end{array}$ & $\begin{array}{c}\text { Low-salt bread } \\
\text { (mean } \pm \text { SD) }\end{array}$ & $\begin{array}{c}\text { Mean change between } \\
\text { low- and normal-salt } \\
\text { bread (95\% Cl) }\end{array}$ & $P$ value \\
\hline 24-hour urinary sodium excretion & & & & \\
(milliequivalents per 24 hours) & $165.3 \pm 60.3$ & $140.1 \pm 53.3$ & $-25.3(-6.9$ to -43.7$)$ & 0.0086 \\
Systolic blood pressure (mmHg) & $114.4 \pm 8.2$ & $112.71 \pm 7.8$ & $-1.7(-0.5$ to -2.8$)$ & 0.0056 \\
Diastolic blood pressure (mmHg) & $67.6 \pm 4.9$ & $66.88 \pm 4.6$ & $-0.8(-0.1$ to -1.4$)$ & 0.0286 \\
\hline
\end{tabular}

Note: SD: standard deviation, Cl: confidence interval.

FIGURE 1. Change in 24-hour urine sodium by group ( $A=$ normal sodium, $B=$ low sodium), Argentina, 2007

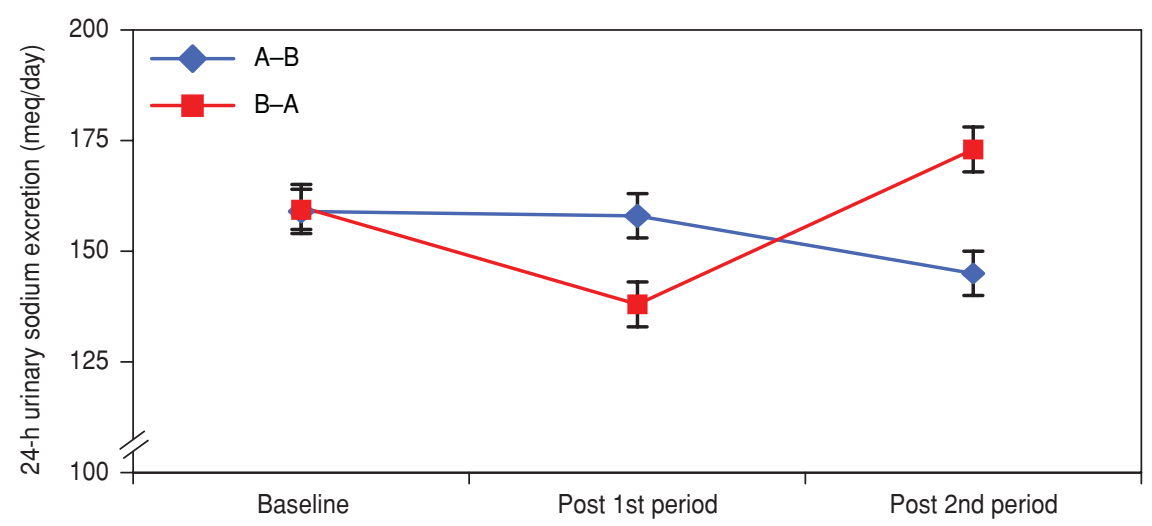

teers. These volunteers could not detect the difference between products. The intervention in bakeries was feasible and did not imply additional costs for bakers or consumers. Reduction in daily sodium excretion estimated at 25 meq is equivalent to a salt intake reduction of 1.2 to $1.4 \mathrm{~g}$.

Previous experiences in developing countries focused on communication campaigns and changes in use of table salt (31). However, in many developing countries most salt intake comes from reduce salt concentration, the development of lower-salt bread that is still acceptable to consumers is feasible and could represent a good opportunity to have a positive impact on the population. As hypertension is the leading cause of burden of disease in Argentina, a public policy to reduce salt intake seems to be a worthwhile recommendation. Moreover, in the context of difficult access to blood pressure monitoring and chronic treatment (19), population-based strategies such as salt reduction in processed foods can be highly cost-effective not only for people with hypertension but also for the general population.

The limitations of this study include financial constraints that did not allow for analyzing a larger sample and those related to crossover experiments (26), which typically include using the same subjects as controls, and the uncertainty of carryover effects. A carryover effect was not relevant in any of the three analyses. For blood pressure reduction, the study was underpowered, and biases in measurements could have been introduced, as digital measurements of blood pressure were not implemented. However, evaluators were blind to the assigned groups, thus making observers' biases less unlikely.

Although this experiment contributed to testing the methods for assessment of acceptability of salt-reduced products, a wider assessment of consumer preferences in representative samples around the country is needed. In the same direction, ways to implement the changes in bread production need to be planned using these lessons learned but on a larger scale.

In Argentina, after these results were available, a wider implementation and evaluation was suggested, also including local communication strategies. Similar strategies could be applied to other food products, considering Argentina's consumption patterns and technological feasibility.

The public health implications of these results could be relevant even when the amount of reduction in salt intake is small. A reduction of only $1 \mathrm{~g}$ per person per day in salt intake could avoid thousands of cardiovascular events per year in Argentina. In addition to the high consumption of bread in Argentina, Argentinean bread has higher amounts of salt than bread in other countries, such as the United States of America (1.75\%), New Zealand (1.3\%), and Australia (1.1\%) (32). 
A further reduction accomplished by including more food sectors, changing the local codex alimentarius reducing maximum approved salt concentrations, appropriate labeling, health warnings, and implementing communication and education campaigns could produce a significant reduction in salt intake and therefore have a greater impact on cardiovascular events.

This study describes an experience with one relevant sector of the food chain and shows promising results. Countries in the Americas have expressed their will to work in reducing the population's salt intake, supported by the Pan American Health Organization, and Argentina has already started this process (33). The World Health Organization also advocates for countries to start actions to reduce salt consumption, and these recommendations are supported by current evidence of the excess risk imposed by an elevated salt intake (34).
Salt levels in bread are high, contributing significantly to overall salt intake. However, a reduction in salt concentration is feasible, is well accepted, and results in a reduction in salt intake that could be related to a significant public health benefit. This approach could apply to other food sectors. Other countries in the Americas, with diet patterns similar to those in Argentina, could advance in a similar direction and learn from its successes and failures.

\section{REFERENCES}

1. Murray CJ, Lauer JA, Hutubessy RC, Niessen L, Tomijima N, Rodgers A, et al. Effectiveness and costs of interventions to lower systolic blood pressure and cholesterol: a global and regional analysis on reduction of cardiovasculardisease risk. Lancet. 2003;361(9359):717-25.

2. Statistics and Informatics Department, Ministry of Health, Argentina. Anuario 2009. Buenos Aires: Statistics and Informatics Department, Ministry of Health, Argentina; 2009. Available from: http:/ / www.deis.gov.ar. Accessed 12 July 2010.

3. Intersalt Cooperative Research Group. Intersalt: an international study of electrolyte excretion and blood pressure. Results for 24 hour urinary sodium and potassium excretion. BMJ. 1988;297(6644):319-28.

4. He FJ, MacGregor GA. How far should salt intake be reduced? Hypertension. 2003;42(6): 1093-9.

5. Asaria P, Chisolm D, Mathers C, Ezzati M, Beaglehole R. Chronic disease prevention: health effects and financial costs of strategies to reduce salt intake and control tobacco use. Lancet. 2007;370(9604):2044-53.

6. Law M, Frost D, Wald N. By how much does dietary salt reduction lower blood pressure? BMJ. 1991;302:811-5.

7. He FJ, MacGregor GA. Effect of longer-term modest salt reduction on blood pressure. Cochrane Database Syst Rev. 2004;(3):CD004937.

8. Hooper L, Bartlett C, Davey SG, Ebrahim S. Advice to reduce dietary salt for prevention of cardiovascular disease. Cochrane Database Syst Rev. 2004;(1):CD003656.

9. Ebrahim S, Smith GD. Exporting failure? Coronary heart disease and stroke in developing countries. Int J Epidemiol. 2001;30(2):201-5.

10. Cook NR, Cutler JA, Obarzanek E, Buring JE, Rexrode KM, Kumanyika SK, et al. Long term effects of dietary sodium reduction on cardiovascular disease outcomes: observational follow-up of the trials of hypertension prevention (TOHP). BMJ. 2007. 28;334(7599):885-8.

11. Pietinen P, Tanskanen A, Nissinen A, Tuomilehto J, Puska P. Changes in dietary habits and knowledge concerning salt during a community-based prevention programme for hypertension. Ann Clin Res. 1984;16 (Suppl 43):150-5.
12. Sellers DE, Crawford SL, Bullock K, McKinlay JB. Understanding the variability in the effectiveness of community heart health programs: a meta-analysis. Soc Sci Med. 1997;44(9): 1325-39.

13. Cappuccio FP, Kerry SM, Micah FB, PlangeRhule J, Eastwood JB. A community programme to reduce salt intake and blood pressure in Ghana. BMC Public Health. 2006;24: 6-13.

14. Chang HY, Hu YW, Yue CS, Wen YW, Yeh WT, Hsu LS, et al. Effect of potassiumenriched salt on cardiovascular mortality and medical expenses of elderly men. Am J Clin Nutr. 2006;83(6):1289-96.

15. Rossouw JE, Jooste PL, Chalton DO, Jordaan ER, Langenhoven ML, Jordaan PC, et al. Community-based intervention: the Coronary Risk Factor Study (CORIS). Int J Epidemiol. 1993;22(3):428-38.

16. Tunstall-Pedoe $\mathrm{H}$, Connaghan J, Woodward M, Tolonen H, Kuulasmaa K. Pattern of declining blood pressure across replicate population surveys of the WHO MONICA project, mid-1980s to mid-1990s, and the role of medication. BMJ. 2006;332(7542):617-8.

17. Food Standards Agency. Impact assessment of the revised salt reduction targets. London: Food Standards Agency; 2009. Available from: http://www.food.gov.uk/multimedia/ pdfs/consultation/iarevsaltredtargets.pdf. Accessed 12 July 2009.

18. Task Force on Community Preventive Services. Tobacco. In: Zaza S, Briss PA, Harris $\mathrm{KW}$, eds. The guide to community preventive services: what works to promote health? Atlanta: Oxford University Press; 2005. Pp. 3-79.

19. Ferrante D. Encuesta Nacional de Factores de Riesgo 2005. Buenos Aires: Ministerio de Salud; 2005. Available from: http://www. msal.gov.ar/htm/site/enfr/index.asp. Accessed 12 July 2009

20. Ministry of Health. Argentina saludable. Buenos Aires: Ministry of Health; 2007. Available from: http:/ / www.msal.gov.ar/argentina saludable/. Accessed 12 July 2009.

21. Encuesta Nacional de Nutrición y Salud. Buenos Aires: Ministry of Health. Available from: http://www.msal.gov.ar/htm/Site/ ennys/site/default.asp. Accessed 12 July 2009.
22. Daily bread per capita consumption in Argentina. Enfasis Alimentación Online. Available from: http://www.alimentacion.enfasis. com/notas / 8288-Argentina:-una-de-lospa\%C3\%ADses-con-mayor-consumo-perc\%C3\%A1pita. Accessed 12 July 2009.

23. Rubinstein A, García Martí S, Souto A Ferrante D, Augustovski F. Generalized costeffectiveness analysis of a package of interventions to reduce cardiovascular disease in Buenos Aires, Argentina. Cost Eff Resour Alloc. 2009;6:7-10.

24. Chen M, Hsieh Y, Weng Y, Chiou R. Flame photometric determination of salinity in processed foods. Food Chem. 2005;4:765-70.

25. International Organization for Standardization. Sensory analysis-general guidance for the selection, training and monitoring of assessors. Geneva: Norm ISO-8586-1; 1993.

26. McCulloch CE, Searle SR, eds. Linear models. In: Generalized, linear, and mixed models. Wiley Series in Probability and Statistics. Hoboken, NJ: Wiley; 2008. Pp. 114-35.

27. Mills EJ, Chan AW, Wu P, Vail A, Guyatt GH, Altman DG. Design, analysis, and presentation of crossover trials. Trials. 2009;10:27.

28. Recommendations for blood pressure measurement in humans and experimental animals. Part 1: blood pressure measurement in humans. A statement for professionals from the subcommittee of professional and public experimental animals. Hypertension. 2005;45: 142-61.

29. Skillings J, Weber D, eds. Crossover studies. In: A first course in the design of experiments: a linear models approach. Boca Raton: CRC Press; 2000. Pp. 588-95.

30. Cappuccio FP, Kerry SM, Micah FB, PlangeRhule J, Eastwood JB. A community programme to reduce salt intake and blood pressure in Ghana. BMC Public Health. 2006;6:13.

31. Gaziano T, Galea G, Reddy KS. Scaling up interventions for chronic disease prevention: the evidence. Lancet. 2008;371(9611):473.

32. Thompson B. Nutritional modelling: distributions of salt intake from processed foods in New Zealand. Br J Nutr. 2009;102:757-65.

33. Mobilizing dietary salt reduction in the Americas. Meeting report. Miami, FL: Public Health Agency of Canada World Health Organiza- 
tion Collaborating Center on Chronic NonCommunicable Disease Policy; 2009. Available from: http://www.paho.org/english/ ad/dpc/nc/salt_mtg_rpt.pdf. Accessed 20 August 2010.
34. Less salt, less risk of heart disease and stroke. WHO forum on reducing salt intake in populations. Reducing salt intake in populations: report of a WHO forum and technical meeting, Paris, 5-7 October 2006.
Manuscript received on 21 April 2010. Revised version accepted for publication on 23 November 2010.

RESUMEN Objetivo. Evaluar una intervención destinada a reducir el consumo de sal a partir de un convenio con la industria alimentaria.

Factibilidad de reducir el contenido de sal

\section{de los alimentos procesados} en la Argentina

Métodos. Se midió el contenido de sal de los productos de panadería por medio de una encuesta nacional y análisis bioquímicos. Un grupo de catadores evaluó el pan con bajo contenido de sal para determinar si la disminución pasaba inadvertida. Dado que el pan francés representa $25 \%$ del consumo total de sal en la Argentina, se propuso someter a prueba este tipo de pan con una disminución de la concentración de sal de $2 \%$ a $1,4 \%$. Se realizó un estudio cruzado con el fin de evaluar si los participantes presentaban una concentración urinaria de sodio más baja y una presión arterial menor durante el período en que consumieron pan con bajo contenido de sal respecto del período en que consumieron pan común.

Resultados. El pan común contiene un porcentaje promedio de sal de $2 \%$. En este estudio, el pan con bajo contenido de sal contenía 1,4\%, disminución que, en general, pasó inadvertida a los catadores. En el estudio cruzado, en el que participaron 58 sujetos, la eliminación urinaria de sodio disminuyó 25 miliequivalentes en 24 horas, la presión arterial sistólica bajó $1,66 \mathrm{mmHg}$ y la presión arterial diastólica bajó 0,76 $\mathrm{mmHg}$ durante el período en que los participantes consumieron pan con bajo contenido de sal.

Conclusiones. El estudio demuestra que es factible reducir la ingesta de sal alimentaria y que la población estudiada considera aceptable que el pan contenga esta menor concentración de sal. Aunque los efectos sobre la concentración urinaria de sodio y la presión arterial fueron moderados, es probable que una intervención nacional tenga repercusiones más importantes para la salud pública.

Palabras clave Sodio en la dieta; hábitos alimenticios; política nutricional; pan; presión sanguínea; Argentina. 